\title{
A Study on IoT-based Fleet Maintenance Management
}

\author{
Kangbae Lee ${ }^{1}$, Doo-hwan Kim ${ }^{*}$, Hyung Rim Choi ${ }^{2}$, Byung Kwon Park ${ }^{3}$, Min Je \\ $\mathrm{Cho}^{4}$ and Dong Yeon Kang ${ }^{5}$ \\ 1, *, 2, 3, 4, 5 Department of Management Information Systems, Dong-A University, \\ Republic of Korea \\ ${ }^{1}$ kanglee@donga.ac.kr, ${ }^{*} k d h b l a c k @ d o n g a . a c . k r,{ }^{2} h r c h o i @ d a u . a c . k r$, \\ ${ }^{3}$ bpark@dau.ac.kr, ${ }^{4}$ mjcho@dau.ac.kr, ${ }^{5}$ ghkxk01@donga.ac.kr
}

\begin{abstract}
In fleet management, fleet maintenance is a crucial aspect to increase availability. Periodic and preventive maintenance is conducted for the fleet regardless of the level of practical faults. This triggers repair and component replacement costs, as well as consumption of time. With the development of the information and communications technology, the Internet of Things (IoT) is under focus and being applied in various industries. This technology can also be used to perform predictive fleet maintenance. Thus, this study defines a fleet maintenance management system (FMMS) based on the IoT by applying the soft system methodology and determines the role of stakeholders according to the CATWOE method. An IoT-based FMMS conceptual model is also proposed on the basis of the definition above. IoT-based predictive maintenance can increase fleet availability, stability, and efficiency; reduce cost through effective maintenance planning; and eliminate unnecessary maintenance tasks.
\end{abstract}

Keywords: IoT, SCM, fleet management, real-time, predictive maintenance

\section{Introduction}

Supply chain management (SCM) is an overall activity for satisfying customer needs and reducing the cost of supply chain across the activities of suppliers and consumers, right from the acquisition of raw materials to product manufacturing, transport and shipment, and sales [1-2]. The reduction of transport cost, which accounts for $1 / 3$ to $2 / 3$ of the entire distribution cost under the SCM environment, leads to a decrease in the operating cost of the supply chain, including consumers, transport and logistics firms, and suppliers [3].

Fleet management is crucial for cost reduction in the supply chain. It aims to improve fleet scheduling and increase operational efficiency and effectiveness. It also includes information management and processes for fleet maintenance and routing problems [4]. Although a fleet contains equipment (i.e., vehicles, railways, airplanes, ships, and heavy equipment) used in several industries, the term typically reflects vehicles. Fleet maintenance management is a process of allocating and scheduling resources for activities (i.e., repair, replacement, and preventive maintenance) related to the fleet [5-6]. Efficient fleet maintenance management can be conducted only when these three conditions are satisfied. First, a transport process should be the main process that yields corporate profits. Second, a process of converting the "unready for operation" state of fleet to the "ready for operation" state should be established. Third, a technical test for fleet maintenance should assure safety and environmental protection [7-8].

\footnotetext{
${ }^{1}$ First Author

* Corresponding Author
} 
With the development of the information and communications technology (ICT), the Internet of Things (IoT) is under focus and being applied to provide real-time information through intellectual communication among humans and objects in various industries. As this technology can solve a problem related to the limitations of radio-frequency identification (RFID), a communication module can be equipped to the IoT equipment to facilitate real-time network communication [9-11]. The application of the IoT technology can combine information and minimize the gap between the flow of distribution and information, thereby leading to effective supply chain management [12].

Several studies on the vehicle routing problem (VRP) have been carried out to solve routing problems [13-15]. In terms of fleet maintenance, much research has been conducted on increasing fleet reliability and performing the maintenance of multi-systems consisting of multiple components [16-18]. However, few studies have examined fleet maintenance management by applying the ICT (IoT) technology.

Thus, this study identifies the problems in fleet management and defines the concept of the IoT-based fleet maintenance management system (FMMS) by applying the soft system methodology (SSM) based on the problems indicated. Moreover, the role of related agents is determined on the basis of the concept defined and the CATOW method. In addition, the IoT-based FMMS conceptual model is proposed.

\section{Concept and Characteristics of SSM}

The SSM proposed by Checkland [19-20] aims to address complex social problems smoothly by abstracting and simplifying them in the form of a conceptual model instead of a certain analytic or evaluation method. For this reason, it indicates a systematic research methodology that supports the process of addressing complex social problems in a simple and smooth way by generating an abstract conceptual model and verifying the extent of this model for reflecting social problems through an evaluation process.

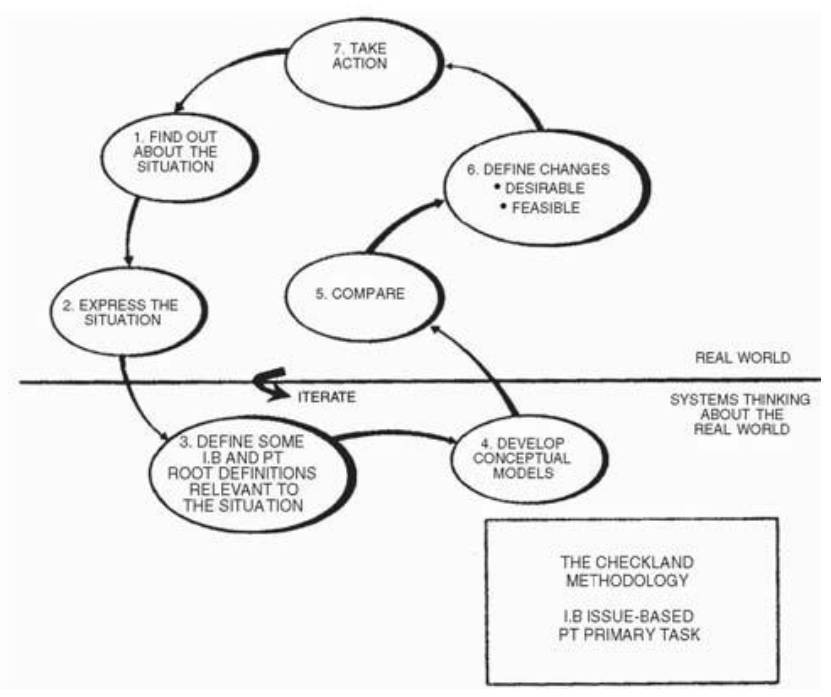

Figure 1. SSM Procedure

As the SSM intends to assist the formulation and structuration of problems related to various and complex human behaviors, the core of this methodology is based on the following conditions: the conceptual model should be established by systematizing and identifying the pattern of human activity, and this model should be compared with the practical world for validation. The SSM solves a problem through phased procedure under the main frame indicated above. The detailed procedure for applying the SSM consists of seven stages because the division of a complex soft system based on decision-making 
stages makes it easy to draw a solution. Figure 1 shows the entire procedure of SSM and Table 1 presents the phased procedure of SSM and relevant details.

Table 1. Seven Stages of SSM

\begin{tabular}{|c|c|c|}
\hline Stage & Domain & Job description \\
\hline 1 & $\begin{array}{c}\text { Real } \\
\text { World }\end{array}$ & $\begin{array}{l}\text { - Enter situation considered problematical } \\
\text { - The researcher makes a few presumptions about the nature of } \\
\text { the situation as possible }\end{array}$ \\
\hline 2 & $\begin{array}{l}\text { Real } \\
\text { World }\end{array}$ & $\begin{array}{l}\text { - Express the problem situation } \\
\text { - The researcher develops a detailed description, a "rich picture" } \\
\text { of the situation within which the problem occurs }\end{array}$ \\
\hline 3 & $\begin{array}{l}\text { System } \\
\text { Thinking }\end{array}$ & $\begin{array}{l}\text { - Formulate root definitions of relevant systems of purposeful } \\
\text { activity } \\
\text { - For the logical analysis, the researcher provides the checklist for } \\
\text { ensuring that the important features of the root definitions are } \\
\text { included }\end{array}$ \\
\hline 4 & $\begin{array}{l}\text { System } \\
\text { Thinking }\end{array}$ & $\begin{array}{l}\text { - Build conceptual models of the systems named in the root } \\
\text { definitions } \\
\text { - The researcher develops descriptions, in system terms, of how } \\
\text { the relevant parts of the situation might ideally function }\end{array}$ \\
\hline 5 & $\begin{array}{l}\text { Real } \\
\text { World }\end{array}$ & $\begin{array}{l}\text { - Comparing models with real-world situations } \\
\text { - The differences can be used as the basis for a discussion: how } \\
\text { the relevant systems work, how they might work }\end{array}$ \\
\hline 6 & $\begin{array}{c}\text { Real } \\
\text { World }\end{array}$ & $\begin{array}{l}\text { - Define possible changes that are both possible and feasible } \\
\text { - Desirable: is it technically an improvement? } \\
\text { - Feasible: does it fit the culture? }\end{array}$ \\
\hline 7 & $\begin{array}{c}\text { Real } \\
\text { World }\end{array}$ & - Take action to improve the problem situation \\
\hline
\end{tabular}

As mentioned in the table above, the SSM defines a problem in the first stage; expresses the problem in the form of a figure to identify it intuitively in the second stage; defines and describes the role of system-related stakeholders for achieving goals based on the Customers, Actors, Transformation Process, World-View, Ownership, Environment Constraints (CATWOE) method in the form of sentences in the third stage; generates a conceptual model showing schematic description based on the sentences described in the fourth stage; compares the conceptual model derived with practical problems in the fifth stage; evaluates the comparative results to identify improvement points in the sixth stage; and derives measures and strategies that can be implemented to solve the problem in the seventh stage. 


\section{Application and Analysis of SSM}

\subsection{Stages One and Two of SSM}

\subsubsection{Structure of Freight Transport}

Among the freight transportation performed through shipping, railways, flights, and public roads, transportation through trucks on public roads accounts for $75.9 \%$ (Unit: million tons-km) of the entire freight transport and shows an annual increase [21]. As the ratio of transport using trucks on the public roads is significantly high, inappropriate operation of such transport due to mistimed vehicle maintenance increases the penalty cost pertaining to the freight transported [22].

\subsubsection{Technical Limitations}

The RFID technology is applied to ensure the traceability and visibility of products based on information synchronization in the SCM environment [23]. Such advancement of ICT reduces cost and innovates processes through information exchange in the supply chain [24-25]. However, this technology requires an RFID reader to receive product information included in RFID tags attached to products. Therefore, tag information cannot be read without an RFID reader or recognized when a metal material exists between a tag and a reader [26]. In contrast to the RFID technology, the IoT technology can obtain information in real-time through real-time network communication [9-11].

\subsubsection{Maintenance Environment}

The activity of maintenance is conducted to operate a system properly, maintain the quality of system at a certain level or higher through constant maintenance, and make possible its availability at all times [5-6]. Frequent maintenance not only ensures high system reliability, but it also entails high costs. On the contrary, a long maintenance cycle reduces costs, but compromises on reliability. Maintenance is classified into periodic maintenance performed after a certain period of time or when a fault occurs and preventive maintenance, including the tasks of repair and replacement conducted before the fault occurs. As maintenance tasks affect the availability of the entire system that is complex and contains several components, preventive maintenance planning is crucial [27]. However, existing studies mainly focus on increasing the availability of the entire system to a certain level or higher by considering the reliability of sub-components of a system. The method of obtaining data by applying the IoT technology to a fleet can be utilized to determine the reliability of the sub-components of a system in real time. The availability of the entire system can be estimated based on the analytic results of the reliability of each sub-system.

\subsection{Stage three of SSM}

The concept of IoT-based FMMS targeted in this study can be defined according to the SSM method as follows.

"The IoT-based FMMS (X), which provides and supports a predictive maintenance environment for a fleet manager, a driver, and a maintenance technician, is established and managed through real-time fleet data collection and analysis based on the IoT $(\mathrm{Y})$ in order to increase the efficiency and stability of fleet (maintenance) management (Z)."

The role of stakeholders related to the system can be defined based on the CATWOE method as follows. 
- Customers

- Fleet manager

- Driver

- Maintenance technician

- FMMS

- Actors

- Fleet manager

- Driver

- Maintenance technician

- FMMS

- Transformation Process

- A change from periodic maintenance and preventive maintenance to predictive maintenance in terms of efficiency, stability, and system availability

- World-View

- Importance of increasing the efficiency of entire fleet management through the IoTbased FMMS and identifying elements that might affect planning, routing, and scheduling

- Ownership

- Fleet manager

- Driver

- FMMS user

- Environmental Constraints

- Internal and external environments for stakeholders (i.e., shippers, transport firms, distribution firms, and vehicle managers) related to fleet management, information technology (IoT device, database, server, etc.) for fleet maintenance management, data quality, and data process algorithm

\subsection{Stage Four of SSM}

Figure 2 depicts the conceptual system model based on the concept of IoT-based FMMS and relevant role defined. This model is mainly based on predictive maintenance in terms of efficiency, stability, and system availability.

The sensing of fleet data is performed through an IoT sensor attached to a fleet. Data obtained through the sensing process are transferred to a terminal attached to the fleet and then to the FMMS through Wi-Fi, 3G, and LTE communication provided by the terminal. The FMMS analyzes the data obtained and transmits the analytic results to the fleet manager who subsequently reviews the results to inform the driver, operator, and maintenance technician about the accident risk during driving or need for maintenance, or send notification messages to them. The maintenance technician prepares necessary components and equipment for maintenance, and the driver of a vehicle that requires maintenance receives the maintenance service at a designated repair shop or garage.

Periodic and preventive maintenance is typically conducted when a fault occurs or a replacement cycle of components arrives. On the other hand, the IoT-based FMMS can perform predictive maintenance that assures efficient maintenance and fleet stability. It does so by analyzing the data obtained to examine the reliability of components that affect the availability of the fleet system and considering maintenance resources and time to increase the availability of the entire system. 


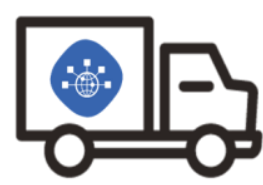

IoT based Fleet Data Sensing

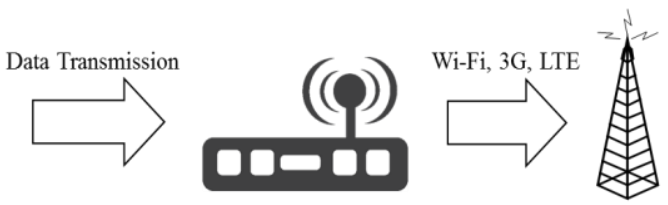

Terminal/Device on the Fleet

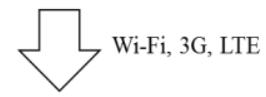

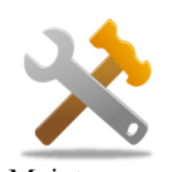

Maintenance

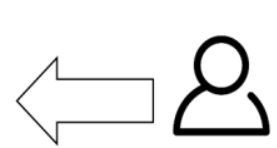

Driver, Operator Maintenance Technician

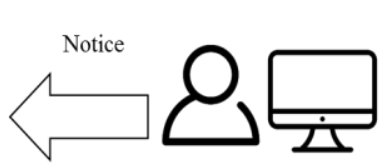

Fleet Manager
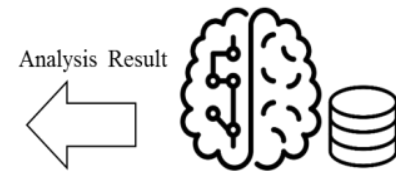

Fleet Maintenance Management System

Figure 2. IoT-based Fleet Maintenance Management Conceptual Model

\subsection{Stages Five to Seven of SSM}

Preventive maintenance has been carried out to increase the availability of the fleet. However, as such maintenance is performed without considering the level of practical fault, it increases costs due to frequent down time and component replacement [27]. Limited monitoring in preventive maintenance might reduce the remaining life of the component or machine, and unnecessary idle time can also occur. However, the advancements in the ICT technology have established an environment where data on the state of the system can be analyzed in real time, thus facilitating predictive maintenance that can reduce cost and increase availability. Moreover, the faults in the fleet can be estimated through real-time monitoring, and idle time caused by the maintenance process can be minimized based on the remaining life of the component.

Furthermore, the IoT sensor attached to a fleet obtains data in real time and the FMMS analyzes the data comprehensively to estimate the point of faults in the fleet. Predictive maintenance can be conducted based on the point of fault estimated, and cost can be reduced through the optimization of fleet maintenance planning. To perform the predictive maintenance of the fleet, the FMMS should estimate the remaining life and reliability of the components and analyze fault patterns based on the data obtained through IoT sensors. As fleet data are generated in the form of low data by IoT sensors, those formed in real time become big data, showing an enormous volume. The database for distributed storage should be established in the FMMS to store the big data, and a structure based on the scale out method should be designed. In addition, a machine learning algorithm is required to analyze the data obtained and estimate the remaining life and point of faults. When these conditions are fulfilled, the IoT-based FMMS can perform predictive maintenance that increases maintenance efficiency and stability as well as system availability.

\section{Conclusions}

This study has defined the IoT-based FMMS by applying the SSM and determined the role of stakeholders according to the CATOW method. The IoT-based FMMS conceptual model has also been proposed based on the concept and role defined. Data generated in real time by the IoT sensor attached to the fleet are transferred to the terminal/device of the fleet and then to the FMMS through Wi-Fi, 3G, and LTE communication. The FMMS analyzes the data obtained and the past data to estimate the system availability, remaining life of the product, and point of faults, and transmits the analytic results to the fleet 
manager. The fleet manager identifies the state of the fleet that faces potential threats based on the results and informs the driver and maintenance technician about the need for maintenance. As the analytic results derived from the FMMS indicate the components that require repair and maintenance, the maintenance technician can set up a maintenance plan by calculating maintenance time and preparing necessary components in advance. The IoT-based FMMS removes idle time caused by unnecessary maintenance tasks by conducting predictive maintenance and assists efficient maintenance planning through real-time monitoring. Furthermore, it reduces maintenance costs by identifying the components that can lead to a decrease in these costs in terms of remaining life and system availability.

\section{Acknowledgments}

This work was supported by the Ministry of Education of the Republic of Korea and the National Research Foundation of Korea (NRF-2015S1A5A2A03048940).

This paper is a revised and expanded version of a paper entitled [A Study on Vehicle Routing Problems Considering IoT based Real Time Information] presented at Doo-hwan Kim, Jeju University, (2016) December 21-23.

\section{References}

[1] Cachon, Gérard P., and Marshall Fisher., "Supply chain inventory management and the value of shared information," Management science, vol. 46, no. 8, (2000), pp. 1032-1048.

[2] Wisner, Joel D., and Keah Choon Tan, "Supply Chain Management and Its Impact on Purchasing" Journal of Supply Chain Management, vol. 36, no. 3, (2000), pp. 33-42.

[3] Yoon, T.Y. and Lee, S.H., "A heuristic algorithm for the periodic heterogeneous fleet vehicle routing problem”. The Korean Operations Research and Management Science Society, vol. 36, no. 1, (2011), pp.27-38.

[4] Auernhammer, H., "Precision farming-the environmental challenge", Computers and Electronics in Agriculture, vol. 30, no. 1, (2001), pp. 31-43.

[5] Ben-Daya, M. and Duffuaa, S.-O., "Maintenance and quality: the missing link", Journal of Quality in Maintenance Engineering, vol. 1, no. 1, (1995), pp. 20-26.

[6] Cassady, C. R., Murdock, W. P., Nachlas, J. A., and Pohl, E. A., "Comprehensive fleet maintenance management." Systems, Man, and Cybernetics, IEEE International Conference on, (1998). vol. 5, pp. 4665-4669.

[7] Zhu, G., and Pintelon, L., "Integrated production maintenance management (IPMM) as an enterprise approach to maintenance management". In Proceedings of IIE annual conference, (2001).

[8] Zhu, G., Gelders, L., and Pintelon, L., "Object/objective-oriented maintenance management", Journal of Quality in Maintenance Engineering, (2002), vol. 8, no. 4, pp. 306-318.

[9] Moon, Y.S., Jung J.W., Choi S.P., Kim, T.H., Lee, B.H., Kim, J.J., and Choi, H.R., "Real-time Reefer Container Monitoring System based on IoT", Journal of the Korea Institute of Information and Communication Engineering, (2015), vol. 19, no. 3, pp. 629-635.

[10] B.K., Park, H.R., Choi, C.S., Kim, K.B., Lee, and M.S., Park, "Development of Simulation System For Real-Time Location Tracking In Global Shipping Logistics", Journal of the Korea Institute of Information and Communication Engineering, (2015), vol. 19, no. 5, pp. 1235-1242.

[11] Kim, T.H., Lee, B.H., Park, B.K., Choi, S.P., Moon, Y.S., Jung, J.W., Kim, J.J., Choi, H.R., “Active IPRFID System for Maritime Logistics", The Journal of Korean Institute of Communications and Information Sciences, (2015), vol. 40, no. 12, pp. 2511-2519.

[12] Verdouw, C. N., A. J. M. Beulens, and J. G. A. J. Van der Vorst, "Virtualisation of floricultural supply chains: A review from an Internet of Things perspective", Computers and electronics in agriculture, (2013), vol. 99, pp. 160-175.

[13] Eiichi Taniguchi and Hiroshi Shimamoto, "Intelligent transportation system based dynamic vehicle routing and scheduling with variable travel times", Transportation Research Part C: Emerging Technologies, (2004), vol. 12, no, 3, pp. 235-250.

[14] Kim, K.T, and Cho, S.J, "A Hybrid Genetic Algorithm for Vehicle Routing Problem which Considers Traffic Situations and Time Windows, Journal of the Korea Management Engineers Society, (2012), vol. 17, no. 2, pp. 61-75.

[15] Psaraftis, Harilaos N., Min Wen, and Christos A. Kontovas. "Dynamic vehicle routing problems: Three decades and counting", Networks, (2016), vol. 67, no. 1, pp. 3-31.

[16] Schneider, Kellie, and C. Richard Cassady. "Evaluation and comparison of alternative fleet-level selective maintenance models", Reliability Engineering \& System Safety, vol. 134, (2015), pp. 178-187. 
[17] Fatin Amirah, A.S., Ruzanna, M.A, Aishah Ramlan and Mohd Syazwan, M.A, "An Overview of Fleet Maintenance and Operating Cost: Key Components and Methods", International Journal of Commerce, Business and Management, vol. 2, no. 6, (2013), pp. 443-452.

[18] Liu, Yu, and Hong-Zhong Huang. "Optimal selective maintenance strategy for multi-state systems under imperfect maintenance”, IEEE Transactions on Reliability, vol. 59, no. 2, (2010), pp. 356-367.

[19] Checkland, P. B., "Systems Thinking, Systems Practice", John Wiley, Chichester, (1981).

[20] Checkland, P. B., "Soft systems methodology," Human systems management, vol. 8, no. 4, (1989), pp. 273-289.

[21] "2015 Statistical Year Book of MOLIT, MOLIT (Ministry of Land, Infrastructure and Transport), Korea, (2015).

[22] Taniguchi, Eiichi, and Hiroshi Shimamoto, "Intelligent transportation system based dynamic vehicle routing and scheduling with variable travel times", Transportation Research Part C: Emerging Technologies, vol. 12, no. 3, (2004), pp. 235-250.

[23] Wong, K. H., Chan, A. C., Hui, P. C., and Patel, C. A., "A Framework for Data Flow in Apparel Supply Chain Using RFID Technology", Proceedings of the 2006 4th IEEE International Conference on Industrial Informatics, Singapore, (2006) August 16-18.

[24] Won, D.H., 2012. "The influence of SCM activities and SCM performance on export performance in Korean electronics corporations", Journal of Korea Trade, vol. 37, no. 1 (2012), pp.313-334.

[25] Lou, P., Liu, Q., Zhou, Z., and Wang, H., "Agile supply chain management over the internet of things", Proceeding of 2011 International Conference on Management and Service Science, Wuhan, China, (2011) August 12-14.

[26] Kim, S.S., and Kim, Y.H., "Stock Management of Products and Location Tracking System Using RFID Technology", Journal of Security Engineering, vol. 5, no. 5, (2008), pp. 381-392.

[27] Lee, Y.H., Lee, I.D., Lee, D.W., Sohn, K.H., "Optimal Preventive Maintenance Period in Complex Systems in Considering Components Reliability Characteristic", Journal of the Korean Institute of Industrial Engineers, vol. 37, no. 4, (2011), pp. 390-399.

[28] Joo-ho Choi, "Prognostics and Health Management", Journal of the KSME, vol. 3, no. 7, (2013), pp. 2452.

[29] Joo-ho Choi, "A review on prognostics and health management and its applications", Journal of The Society for Aerospace System Engineering, vol. 8, no. 4, (2014), pp. 7-17.

[30] Yoon, J.A., Kim G.K., Kim, J.Y., "A study of new maintenance support equipment based on predictive maintenance", In Proceedings of Korean Institute Of Industrial Engineers Conference, (2016).

[31] Kim, H.G., Kim, W.S., "Reliability Analysis of Multi-Component System Considering Preventive Maintenance: Application of Markov Chain Model", Journal of Applied Reliability, vol. 16, no. 4, (2016), pp. 313-322.

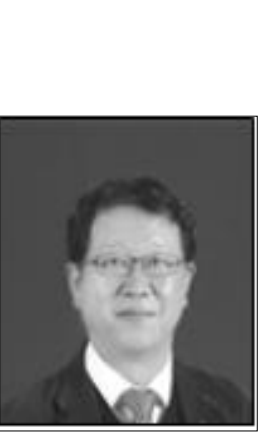

\begin{abstract}
Authors
Kangbae Lee, Professor Kangbae Lee is currently a Professor of MIS at School of Business, Dong-A University. He received his Ph.D. in Industrial Engineering from Korea Advanced Institute of Science and Technology (KAIST). His current research interests include IoT, Supply Chain Management, Fleet Management and Industrial Engineering.
\end{abstract}

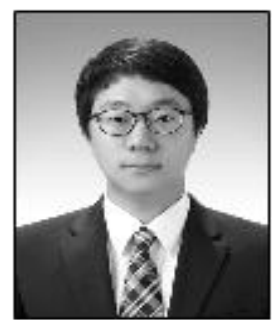

Doo-hwan Kim, Doctor Course Doo-hwan Kim received the Master of Business Administration from Dong-A University. His current research interests include IoT, Supply Chain Management, Big data and Fleet Management. 

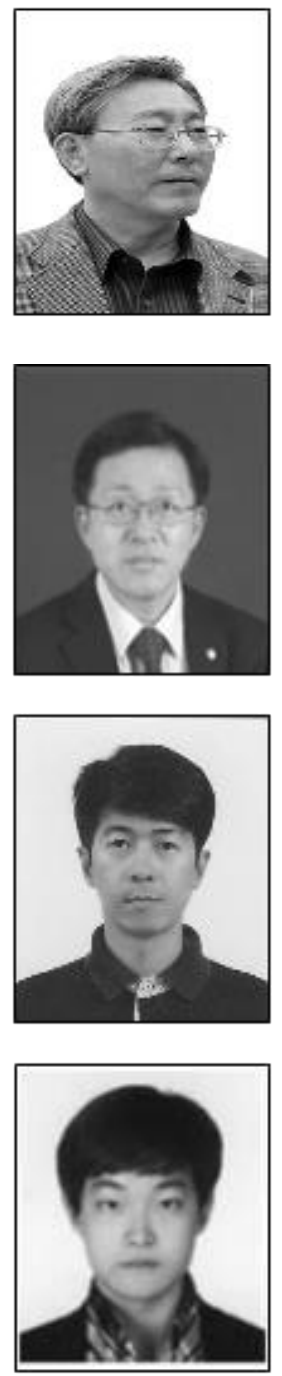

Hyung Rim Choi, Professor Hyung Rim Choi is currently a Professor of MIS at School of Business, Dong-A University. He received his Ph.D. in Management Science from Korea Advanced Institute of Science and Technology (KAIST). His current research interests include IoT, Supply Chain Management, Logistics and Fleet Management.

Byung Kwon Park, Professor Byung Kwon Park is currently a Professor of MIS at School of Business, Dong-A University. He received his Ph.D. in Industrial Engineering from Korea Advanced Institute of Science and Technology (KAIST). His current research interests include IoT, Supply Chain Management, Database and Fleet Management.

Min Je Cho, Professor Min Je Cho is currently a Professor of MIS at School of Business, Dong-A University. He received his Ph.D. in MIS from Dong-A University. His current research interests include IoT, Supply Chain Management, Fleet Management and Business Intelligence.

Dong Yeon Kang, Master course Dong Yeon Kang received the B.S. degree in Political Science and Diplomacy from Dong-A University. His current research interests include IoT, Supply Chain Management, Fleet Management and Demand Forecasting. 
International Journal of Control and Automation Vol.10, No.4 (2017) 